\title{
Leadership of Entrepreneurship at the Macro-Level
}

\author{
Ipeleng MABUSELA and Brian BARNARD*
}

\author{
WITS Business School, University of the Witwatersrand, South Africa
}

\begin{abstract}
The study assesses the state of leadership of entrepreneurship at the macro level. It further explores the effectiveness of leadership; the gaps, issues and challenges; and the roles of government and the private sector with regards to entrepreneurship leadership. At its core, the study challenges the assumption that entrepreneurship must be led by government and considers the alternative proposition that entrepreneurship can be led by itself - by an independent body of entrepreneurs. The research finding is that entrepreneurship is not effectively led: 1) Several private and public sector initiatives exist to support entrepreneurs, but remain largely uncoordinated. 2) There are a lack of standards and benchmarking at the macro level, even though entrepreneurs could benefit from accreditation, guidelines, governance and strategy frameworks. 3) Entrepreneurship lacks a unified voice. 4) The stakeholders of entrepreneurship compete, rather than collaborate. Government does not understand or effectively communicate with entrepreneurs. The private sector does not always have the best interests of entrepreneurs at heart, due to conflicting interests. Incubators, accelerators and universities compete among themselves for funding and accolades, which hinders their assistance to entrepreneurs. 5) Entrepreneurship carries a negative culture. 6) The leadership style applied to entrepreneurship is inappropriate. 7) There is little vision and direction setting for entrepreneurship as industry or fraternity.
\end{abstract}

Keywords: Entrepreneurship, leadership, governance, entrepreneurship policy, macro-level, entrepreneurship industry

JEL Classification: O30, L26

\section{Introduction}

The purpose of the study is to assess the state of leadership of entrepreneurship at the macro level (ELML). The entrepreneurship industry and entrepreneurship fraternity essentially refer to the same thing. It refers to the collective entrepreneurship body or population. Entrepreneurship leadership at the macro level then refers to leadership of and for the entrepreneurship fraternity or entrepreneurship industry. Leadership at industry level may benefit the entrepreneurship industry (EI) by providing vision and direction. A

\footnotetext{
* Corresponding Author:

Brian Barnard, Wits Business School, University of the Witwatersrand, South Africa

Article History:

Received 1 February 2018 | Accepted 13 March 2019 | Available Online 2 December 2019

Cite Reference:

Mabusela, I. and Barnard, B., 2019. Leadership of Entrepreneurship at the Macro-Level. Expert Journal of Business and Management, 7(2), pp.236-255.
}

This paper has previously been included in an open access repository - SSRN. 
demonstration of the benefit of industry leadership is Taiwan's Hsinchu region, that was established through the strong link between Silicon Valley and Hsinchu. Leadership to the industry was provided by Taiwanese engineers who worked in Silicon Valley and brought back their expertise and management skills to bolster the Hsinchu technology industry, which now competes globally with Japan and the U.S. in the manufacturing of notebook computers and other PC components (Saxien, 2000).

On the contrary, incubators typically depict the case of lack of leadership. Incubators have the role of supporting entrepreneurs to network, navigate business related legalities and develop their businesses. This has proven to be problematic even in relatively successful countries such as the U.S, where incubators focus too much time on their own financial sustainability. In Europe incubators struggle to bridge the gap between funders and entrepreneurs and there is a lack of entrepreneurial culture. Even in cases where incubators have been a success, on a macro level these remain scarce, isolated and uncoordinated (Aernoudt, 2004).

Entrepreneurship is a key driver of growth and development across the world, and touches on several aspects ranging from poverty alleviation to economic policy development (Hart, 2003). However, in terms of policy development, several governments have made the fundamental mistake of equating Small to Medium Enterprises (SMEs) to entrepreneurship. Entrepreneurship policy focuses on high impact, newness, and reshaping the manner in which things are done. SME policy does not necessarily focus on these entrepreneurial attributes, but instead focuses on protecting SMEs and more closely depicts incentivised self-employment than entrepreneurship (Henrekson and Stenkula, 2010). Regardless, entrepreneurship policy literature is still scant on details of entrepreneurship leadership at the industry level.

Governance is closely related to policy and both affect the demand side and ultimately supply side of entrepreneurship (Hart, 2003). New governance literature points to the increasing failure of government to address societal issues on its own, and the increasing role of the private sector in conventional areas of governance, and the related success it can introduce. PPPs define the cooperation between government, profitmaking firms, and non-profit private organizations, in order to bring about change in society (Börzel and Risse, 2005). Strategic leadership gives meaning, makes sense of environmental ambiguity, and provides a clear vision that allows the organization to evolve and innovate. At an industry level, this may provide entrepreneurship as an industry with sense of purpose (know-why), meaning (know-what) and methods (knowhow), in order to advance the industry as a whole (Boal and Schultz, 2007).

Globally, entrepreneurship is not approached and led as an industry, but it is instead segregated into regions or industries, interchanged with SMEs, misunderstood by policymakers, and driven by uncoordinated incubators and other private entities. The study further examines the extent and scope of leadership within EI. In particular, it investigates the following:

- What is the effectiveness of EI leadership? What are the gaps within EI leadership?

- What are the issues and challenges within EI leadership?

- What is the role and contribution of government in terms of EI leadership?

- What is the role and contribution of the private sector in terms of EI leadership?

Several studies have focused on leadership in general, as well as applied leadership in the private sector, such as the impact of transformational leadership versus transactional leadership on the psyche of the organization (Elenkov et al., 2005). However, there exists a gap in leadership literature within entrepreneurship, particularly at the industry level, as opposed to the level of the entrepreneur. It of interest to understand the effectiveness, gaps and challenges of EI leadership, in order to recommend areas of improvement that benefit entrepreneurs and their industry.

Public policy means the intentional use of power by government to bring about change. This is significant in the context of entrepreneurship, as policy affects the environment in which entrepreneurs exist, and policymakers often fail to exploit opportunities and counter risks related to entrepreneurship, as they don't not fully comprehend the interaction between entrepreneurship and public policy (Hart, 2003). Government therefore has a significant role to play when it comes to entrepreneurship, and this is well researched in the context of entrepreneurship policy. Still, it equally assumes government must lead entrepreneurship, and that government is the best candidate to lead entrepreneurship. Entrepreneurship policy literature does not adequately address the leadership of entrepreneurship as industry.

The private sector and other non-government agents contribute significantly to the efforts of governments the world over. They offer knowledge, expertise, governance and problem solving capabilities that can be well integrated and managed through PPPs (Börzel and Risse, 2005). The private sector may also act alone, outside of government, for example through initiatives such as incubators to stimulate entrepreneurship (Aernoudt, 2004). The role played by the private sector in EI leadership is yet to be explored in depth. 


\section{Literature Review}

The literature explores three general themes in order to investigate EI leadership: 1) Leadership in the broad sense, 2) Entrepreneurship policy and its difference to SME policy, and 3) Governance by government and cooperation with non-governmental agents.

\subsection{Leadership}

In the context of the study, leadership is seen as crucial to the vision and strategic direction of the entrepreneurship industry. The literature review explores what leadership may look like for entrepreneurship at industry level.

Thomas et al. (2004) note that leadership can instil urgency, commitment, resolve, and awareness or mindfulness. Values themselves can be a driving force. In general, a shift from compliance to commitment is sought. Davies and Davies (2004) see leadership as a process of influence, leading to the achievement of desired purposes. It involves inspiring and supporting others towards the achievement of a vision for the organization which is based on clear personal and professional values. Elenkov et al. (2005) define strategic leadership as the process of forming a vision for the future, communicating it to subordinates, stimulating and motivating followers, and engaging in strategy supportive exchanges with peers and subordinates. Ireland and Hitt (1999) perceive strategic leadership as a person's ability to anticipate, envision, maintain flexibility, think strategically, and work with others to initiate changes that will create a viable future for the organization.

\subsubsection{Transactional and Transformational Leadership}

Elenkov et al. (2005) explain that substantive research exists that supports the power of both transactional and transformational leadership. Transactional leaders concern themselves with the immediate needs of their followers, while transformational leaders look beyond immediate needs and focus on uplifting morale, motivation and morals of their followers. There are three elements of transactional leadership; 1) contingent reward behaviour where the leader clarifies what is required of the follower in order to be rewarded, 2) management by exception behaviour, where the leader monitors the follower's behaviour and takes action if the behaviour is not acceptable, and 3) laissez-faire behaviour, where the leader avoids taking any action at all. There are four main elements in transformational leadership: 1) Leaders exhibit charismatic or idealized influence on their followers, who identify with the leader and want emulate him. Followers perceive such leaders to have superior capabilities. 2) Leaders portray inspirational and motivational behaviour and instill it in their followers. These leaders communicate clear and challenging expectations to their followers. 3) Leaders engage in intellectual stimulation to support their followers in creativity and problem solving through challenging norms within the organization. 4) Leaders appreciate the different needs, strengths, weaknesses and desires of each individual follower. They support, coach and mentor each follower individually and create unique opportunities for growth and learning for each of them (Elenkov et al., 2005).

Even though the two leadership approaches are conceptually different, they are not mutually exclusive. Both approaches may be used by the same managers at different intensities depending on the individual subordinate. The shortcomings from an organizational perspective, however, are significant, as research has focused on the individual level effects, and not beyond the leader's immediate subordinates. Organization wide effects must be studied to gain perspective on these leadership factors (Elenkov et al., 2005).

\subsubsection{Distributed Leadership}

Leithwood et al. (2004) state that the concept of distributed leadership is quite simple: initiatives or practices used to influence members of the organization are exercised by more than a single person; non-person sources of influence also may be included in this concept, thus also leading to a view of leadership as an organization-wide phenomenon. The concept of distributed leadership overlaps substantially with shared, collaborative, democratic and participative leadership concepts. Distributed leadership assumes a set of practices that are enacted by people at all levels rather than a set of personal characteristics and attributes located in people at the top. There are two basic forms of distributed leadership: additive and holistic. Additive forms involve tasks that are dispersed among members of the organization without necessarily considering their interactions. Holistic forms entail focus on the interdependence of those providing leadership. These forms of distributed leadership attribute high levels of interdependence amongst leaders, which leads to high levels of synergy and dynamic, multi-directional social processes that enable learning for individuals and the organization as a whole. In contrast to hierarchical leadership forms, distributed leadership accurately reflects delegation and division of labour on a practical level. This reduces the probability of an error occurring, based on the decision of an individual leader with limited information from a single perspective. 
Leithwood et al. (2004) argue that distributed leadership creates an environment where the capacities of the organization's members can be easily enlisted for the benefit of the entire organization. Greater commitment and buy-in to organizational goals is achieved through members' participation in decisionmaking. Anticipation and response to the organization's environment, team morale and fulfillment are greatly improved due to the self-determination that distributed leadership encourages.

Leithwood et al. (2004) note that coordination amongst leaders in distributed leadership remains challenging. Coordination can be achieved in small teams through direct interaction. However, in large organizations, direct interaction is limited due to practical constraints such as time and logistics. In vertical relationships, two-way flow of information assists with coordination. There must be some tasks or functions that should not be distributed or shared. Top leaders should be assigned the job of deciding on the organization's vision (including its core values), determining an overall strategy for realizing the vision, and making sure the organizational structure supports its strategy. While top leaders are likely to engage many people in processes leading up to such decisions, top leaders have the final responsibility for them. At least partly shareable leadership tasks are: setting goals, vision, support of individuals and creation of collaborative culture. These tasks need to be carried out at all levels of the organization to ensure sustainability.

\subsubsection{Strategic Leadership}

Boal and Schultz (2007) explain that strategic leadership is a series of decisions and activities that are simultaneously process-oriented, rooted in implementation and visionary in nature. Strategic leadership creates a strong link between the past, present and future of the organization, by reaffirming core values and giving a strong sense of identify while navigating the dynamic environment in which the organization functions. Strategic leadership gives meaning and makes sense of environmental ambiguity and provides a clear vision that allows the organization to evolve and innovate. Supervisory theories of leadership focus on personorientated behaviours, as they attempt to support, mentor and give feedback to followers in the organization, while strategic leadership focuses on giving meaning and purpose for the organization, with a clear focus on the organization, instead of in it. Through storytelling, strategic leaders give context and are able to influence the organization's interpretation and promotion of information. This results in the beginning or reaffirming of consensus of organizational purpose (know-why), organizational meaning (know-what) and organizational methods (know-how). Strategic leadership promotes a balance between chaos and order, between the inertia of bureaucracy and anarchy, which results in a fluid, responsive and innovative organization.

Rowe (2001) differentiates between visionary, managerial and strategic leadership. Visionary leadership is concerned with the future of the organization. Visionary leaders have an affinity for risk-taking and are not dependent on the organization for a sense of who they are. They exert influence on people within the organization by evoking images and expectations of the future, altering moods and changing perceptions about what is possible, and in so doing altering the determination of the direction of the future. Even though they have potential to create above average performance for the organizations they lead, their inherent weakness lies in looking too far ahead and making changes for the future that may leave the organization unsustainable in the short term. Managerial leadership has the opposite weakness; it concerns itself with the short term sustainability, but may not consider the future enough. For managerial leaders, goals arise out of necessity instead of dreams, and are based on the organization's past and culture. Managerial leaders are sensitive to the past. Managerial leaders influence only those that they work with, and not the organization as a whole. They engage and support short term, least-cost behavioural activities that boost short term financial performance. Managerial leaders will never exceed above average performance for their organizations, and in the long run may even erode the organizations performance by failing to adapt early enough.

Strategic leadership is the synergy between managerial and visionary leadership. Strategic leaders are able to balance the paradox of visionary long term goal setting with immediate actions on achieving those goals, while maintaining short sustainability of the organization. They have strong, positive expectations of performance from their peers, subordinates, superiors and themselves. There are constraints to implementing strategic leadership, especially within an organization, but it is possible given two conditions that are hard to impose: autonomy and protection. If the management team of a division of an organization is given the autonomy to innovate and protected from stringent and bureaucratic financial controls, strategic leadership may be possible. However, as the smaller part of the larger organization becomes successful from risk-taking and ignoring bureaucracy, the larger managerial organization will want to intervene to mitigate risk (Rowe, 2001).

2.1.4. The Impact of the Leader on the Organization

Rowe (2001) emphasizes that the type of leadership an organization has greatly influences its relative 
success, measured in wealth creation. He posits that managerial leadership can at best maintain wealth that has already been created, and at worst erode this wealth. This is because managerial leadership stifles innovation by focusing on financial stability. Visionary leadership is more volatile than managerial leadership in terms of wealth creation, as it may or may not create value. In cases where visionary leaders do create value, their style of leadership is difficult to emulate for other organizations. Several visionary leaders, such as Steve Jobs at Apple, failed to create wealth without the support of managerial leadership supporting them and consequently had to step down or be removed from their top management positions. Strategic leaders create wealth for their organizations by producing above average performance through balancing the paradox of leading and managing, of focusing on the future while focusing on the present financial stability of the organization. An example of this is GE CEO Jack Welch who strove to reduce the stifling effect of bureaucracy on innovation and creativity, which resulted in one of the highest wealth creation rankings in the 1990s and affected the entire industry. Strategic leaders focus on revolutionary change and not evolutionary change. Strategic leadership is not just for professional managers appointed as CEOs, it also applicable to entrepreneurs.

Resick et al. (2009) state that CEOs serve as public figures for their organizations, and as a result, interact with important external constituency groups such as customers, suppliers, and political officials on a regular basis. Charismatic CEOs create a charismatic image that not only enhances identification among the firm's members, but also increases external stakeholders' identification with the organization and creates an overall favourable reputation for the firm. This external identification and favourable reputation helps the organization to obtain vital resources, build good relations with customers, suppliers, and community and regulatory officials, and even to recruit better employees and is referred to as strategic influence. Transformational CEOs are likely to have a similar effect on external constituents. Through creating a compelling vision for the organization and inspiring commitment to the vision, transformational CEOs may obtain pledges of support and capital from powerful external stakeholders, which could ultimately have a positive impact on organizational outcomes.

\subsubsection{Leadership Process}

Jansen et al. (2009) found support for the hypothesis that transformational leadership is associated with explorative learning, while transactional leadership is associated with exploitative innovation. Transformational leadership therefore encourages members of an organization to challenge institutionalized learning and adopt generative and exploratory thinking processes, while transactional leadership encourages an organization's members to adopt a maintenance role and support refinement, improvement and routinization of existing products, services, processes and competencies. The study also reveals that in dynamic or unstable environments, the transformational leaders were even less likely to become exploitative, and transactional leaders were even less likely to become exploratory. However, a very dynamic environment also did not cause transformational leaders to become more exploratory either. This implies that the relationship between transformational leadership and exploratory innovation is not correlated to environment, it is more internally focused. The same is true for the relationship between transactional leadership and exploitative innovation.

Vera and Crossan (2004) note that organizational structure serves as another repository of learning. An organization's structure reflects the attempt to divide tasks among members and arrange the coordination of the different task activities. Strategic leaders may directly determine their firm's structure through straightforward decisions about its type and elements, or they may do so indirectly through the way information is used and shared and through informal networks and political activities. Organizational forms influence learning because they shape how firms seek and process information about key uncertainties. Mechanistic structures, favoured by transactional leaders, are highly centralized, formalized, and standardized. Reinforcing current routines, mechanistic structures enable individuals and groups to learn more effectively from their experience. In contrast, transformational leadership has been associated with organic structures, which are adaptive, decentralized, and conducive to an extensive set of coordination mechanisms, such as cross-unit committees, integrator roles, shared databases, and matrix structures. Within organic structures, learning is disaggregated, and communication is often lateral. Members recognize their interdependence and are willing to share information to achieve the firm's vision and sustain its effectiveness.

\subsection{Entrepreneurship Policy}

In the context of this study, entrepreneurship policy affects the entrepreneurship industry in various ways; ranging from the supply side to the demand side of entrepreneurship. The literature review below explores issues and challenges related to policy that affects entrepreneurship industry leadership.

Henrekson and Stenkula (2010) support the notion that there is a fundamental difference between entrepreneurship and self-employment or SMEs. The two terms are often used interchangeably which is 
incorrect. Entrepreneurship stems from organisations or individuals that actively renew and reshape the economy. Necessity entrepreneurship, starting a business because other income options are unavailable or unsatisfactory, is a questionable definition of entrepreneurship. Opportunity entrepreneurship, starting a business to take advantage of entrepreneurial opportunity, is a more suitable definition. High impact entrepreneurship commercializes key innovations or disrupts industries through breakthroughs that spur growth in both firms and the economy and generate employment. However, self-employment is a second-best response to unfavourable constitutions and lacks entrepreneurial activities. Also, entrepreneurial activity can occur within existing firms. It is therefore impossible to equate or interchange SMEs and self-employment with entrepreneurship.

Hart (2003) explains that entrepreneurship policy is a vast domain, ranging from local to national levels. It touches on several aspects of society, ranging from poverty alleviation to economic policy development. The focus of entrepreneurship policy is on entrepreneurship; the process of starting and expanding new businesses and affects both incumbent and nascent entrepreneurs.

According to Hart (2003), public policy is defined as government's intentional use of its power to influence certain outcomes, whereas governance is defined as the relationship and interaction between various stakeholders such as government, business and academics. The two ideas are intertwined and affect both the supply and demand side of entrepreneurship. For instance, government may introduce a policy that seeks to increase the number of new entrepreneurs thereby increasing the supply side of entrepreneurship, which has an immediate impact on entrepreneurship. On the other hand, other government policies, such as education and macroeconomic policy have long term effects on entrepreneurship, and it may take over a decade for effects to be realised. Both immediate and long term actions are essential for entrepreneurship policy, but entrepreneurship may not be a driver of long term policies such as education. The effects of entrepreneurship, and in fact public policy, may be negated by other external factors, such the rise and fall of industries, and background, such as location and access to electricity. The entrepreneur himself may not even notice the effects of policy on his success, due the complexity of what makes a successful entrepreneur. Policymakers themselves may not be knowledgeable enough to identify opportunities for improving entrepreneurship. Even though extensive research has been conducted by business schools, this has not necessarily been taught in schools of public policy.

\subsubsection{Entrepreneurship versus SME Policy}

SME policy focuses on factors that affect business success among SMEs. Government expenditure and promotion had positive effects on the growth of SMEs in Indonesia (Bhasin and Venkataramany, 2010).

After the Great Depression, many governments believed that small businesses had an important role in job creation and innovation. Policymaking began to focus on protecting small businesses against the cost advantages inherent to large firms and had the aim of alleviating network, knowledge and learning difficulties. This incentivized self-employment and policy became selective towards certain industries, types of firms and groups of people driven by government agencies (Henrekson and Stenkula, 2010).

Yet new evidence reveals that high rates of new employment are driven by gazelles; small firms which generate the most growth. Super gazelles, large firms with high growth, have the common trait of newness with small firms. Newness is therefore considered the most important factor in high growth firms. It must be noted that newness does not equate to the technology sector, newness spans across several industries and sectors (Henrekson and Johansson, 2010). These new developments have in turn influenced policy discussions, shifting them towards a dynamic economy, rather than targeting small firms to compensate them for their inherent disadvantages.

A summary of the difference between entrepreneurship policy and SME policy is as follows (Henrekson and Stenkula, 2010):

- Quality of entrepreneurship instead of quantity of SMEs.

- Focus on incumbent and nascent entrepreneurial individuals' and their needs instead of protecting SME firms.

- $\quad$ Focus on High Impact Entrepreneurs/Gazelles instead on self-employment/SMEs.

- $\quad$ Focus on enabling entrepreneurship instead of supporting SMEs.

Hart (2003) expands upon entrepreneurship policy, explaining that there is a difference between an entrepreneurial venture and a small business venture. An entrepreneurial venture is infused with novelty and dynamism, often related to technology innovation, such as start-up e-commerce firms, even if the business itself may be small. This is different from a well-established neighbourhood restaurant. Entrepreneurship policy therefore excludes ventures that are neither new nor dynamic. Such policy is often aimed at initiating 
and maintaining networks between stakeholders such as potential suppliers and customers within entrepreneurship.

Public policy influences entrepreneurship as follows: 1) the demand side of entrepreneurship, 2) the supply side of entrepreneurship, 3) the availability of resources and skills, 4) preferences for entrepreneurship, and 5) the decision-making process of entrepreneurs (Henrekson and Stenkula, 2010).

\subsubsection{Aims and Objectives}

Entrepreneurship policy must aim at enabling entrepreneurship. Henrekson and Stenkula (2010) list the following four principles that underpin the entrepreneurial economy: 1) ease of starting and growing a business, 2) generous rewards for productive entrepreneurial activity, 3) disincentives for unproductive activity, and 4) incentives to keep the winners on their toes. Several policy areas may affect more than one principal at once. The principals are expanded below:

\section{$1^{\text {st }}$ Principal - ease of starting and growing a business}

- Deregulation of the economy.

- Cost, time, complexity and minimum capital to start a business

- $\quad$ Liquidity and capital constraints - access to funding.

- A flexible labour market.

- A social security system that is aligned to entrepreneurs.

- $\quad \mathrm{R} \& \mathrm{D}$, commercialization and knowledge spill over.

$2^{\text {nd }}$ Principal - rewards for productive entrepreneurship

- $\quad$ Protection of property rights.

- Taxation aligned to entrepreneurs.

$3^{\text {rd }}$ Principal - Disincentives for unproductive entrepreneurship

- $\quad$ Swift bankruptcy and proper knowledge reuse.

- $\quad$ Business culture towards failure.

$4^{\text {th }}$ Principal -Incentives to keep winners on their toes

- A balance between strong and weak IP laws.

\subsubsection{Implementation}

Dahlstrand and Stevenson (2010) note four different categories of entrepreneurship policy. The first of these is the "SME Policy Add-on", where initiatives are framed around the needs of start-ups or stimulation of entrepreneurship, but are weakly resourced and marginalized.

The second is the "New Firm Creation Policy", where government focuses on the reduction of entry and exit administrative and regulatory barriers, such that the start-up process is simplified for potential entrepreneurs (Dahlstrand and Stevenson, 2010).

The third - "Niche Entrepreneurship Policy" - refers to entrepreneurship efforts targeted around specified groups of the population. Target groups may be segments of the population that are under-represented as business owners, or people with the highest potential for potential high-growth firms - scientific researchers, inventors, university graduates, and people with technology experience (Stevenson and Lundström, 2001). Other groups, such as women, youth and ethnic minorities may be targeted to address social ills that created a barrier to entry for that segment (Dahlstrand and Stevenson, 2010).

The fourth - "Holistic Entrepreneurship Policy" - is comprehensive and covers the full spectrum of entrepreneurship policy objectives. Entrepreneurship policy plays an important role in influencing entrepreneurial performance, but the policy should be closely tailored to the specific needs, capabilities, and institutional structures of each country/ region and innovation system (Dahlstrand and Stevenson, 2010).

Stevenson and Lundström (2001) state that there are three prevailing structural approaches, each with its strengths, problems and challenges. One is umbrella agencies, with special authorities to develop, coordinate and deliver SME policy objectives. Another is a horizontal, multi-ministerial approach: multiministries and levels of government partner in the delivery of a common vision for increasing the level of entrepreneurship and business creation activity in the country. With the vertical or silo approach, the responsibility for different parts of small business/ entrepreneurship is split among several departments, each responsible for its own sector, region or objective, with minimal incentive to collaborate in an integrated fashion.

Stevenson and Lundström (2001) argue that, regardless of structure, there are a series of challenges to overcome: 1) managing the horizontality of the policy issues across many government departments, 2) coordinating activity of different levels of government from federal to local, 3) maintaining links between 
policymakers and entrepreneurs, 4) maintaining links between research and policy, and between policy development and local program delivery, and 5) maintaining linkages with the network of non-government organizations and private sector actors. Sharing a common vision for entrepreneurship development and ensuring that all policymakers and support providers have the knowledge and skills they need to serve the small business client is a big challenge. Another challenge is continuity of effort. With federal government terms of as few as three years and frequent changes of government, it is difficult to maintain a steady policy course.

Bhasin and Venkataramany (2010) state that enterprise promotion systems have their own systems that they wish to advance. The policies for promotion of SMEs did not work well, mainly because of inadequate design of programs and insufficient implementation of government capabilities. The main problems were program coverage, lack of cooperation among government institutions, as well as non-government and executing agencies, and often such programs were not supported by state economic policies. New policies should be developed that focus on using strategic alliances that have shown to contribute to increasing growth, facilitating technology transfer, offering alternative financing resources, providing access to markets, encouraging licensing arrangements, increasing profits, and enhancing a firm's ability to compete.

Bhasin and Venkataramany (2010) argue that entrepreneurship development must be managed in a centralized, integrated and comprehensive manner in one agency. There are too many institutions, there is a lack of a coordinated and integrated approach, and there is no Master Plan for developing SMEs.

Stevenson and Lundström (2001) note that several governments have embarked on an "innovation, competitiveness" agenda to encourage the development of R\&D, technology development and innovative, growth-oriented firms. The Dutch government is targeting techno-starters, the Irish government is encouraging the commercialization of publicly funded and university R\&D initiatives, and Australia is backing innovative, technology-oriented enterprises. Each of these governments, to varying degrees, has linked the innovation agenda to entrepreneurship.

Audretsch (2003) notes that regional entrepreneurship programs are typical of new policies that enable entrepreneurial activity. These entrepreneurial policies are increasingly becoming important instruments of the economic policy portfolio. An interesting example is Germany's five EXIST regions, where start-ups are encouraged through universities and state research facilities. The program has explicit goals: 1) creating an entrepreneurial culture, 2) the commercialization of scientific knowledge, and 3) increasing the number of innovative start-ups and SMEs. Enabling policies, such as the provision of venture capital for research support, have been crucial to the success of several technology/ innovation clusters in developed countries.

Audretsch (2003) notes that the emphasis on Small Business Innovation Research (SBIR) and most public funds is on early stage finance, which is generally ignored by private venture capital.

Stevenson and Lundström (2001) note that in several countries entrepreneurship-oriented research institutes or networks exist. These serve as think tanks for public policy research on entrepreneurship and small business issues. Some country-specific research emphasizes the macro-economic environment for small firms; some of it examines individual and collective small firm characteristics, behaviour and performance; some of it focuses on entrepreneurs and their behaviour; the rest of it examines the field of entrepreneurial culture and potential.

\subsection{Governance}

Governance goes beyond the efforts of government, and encompasses the efforts of elements of society such as the private sector, academic institutions, NGOs and communities to bring about change(Hart, 2003). In the context of this study, governance affects the interaction of entrepreneurs with other stakeholders such as the private sector and government.

\subsubsection{Corporate Governance}

Abor and Adjasi, (2007) note a number of definitions of corporate governance: Corporate governance is concerned with aligning the interest of investors and management to ensure that firms are run to the benefit of investors. It is concerned with the relation between the firm's internal governance and societies' perception of corporate accountability. It includes elements such as cultures, systems, structures and processes that are crucial for the firm structures. It is also seen as the system by which companies are directed and controlled as well as defining the relationship between the company and its stakeholders. Corporate governance systems are the mechanisms that define ownership, behaviour and control of organizations within an economy. These mechanisms may be altered for the better, and create soft laws that are adhered to by companies. It is about supervising and holding to account management teams of organisations. 


\subsubsection{Government and Governance}

Villanueva (2015) notes that in the early twenty-first century, in some Latin American countries, change began to occur in the manner in which public problems were addressed. The state began to collaborate with private and societal agencies to be more responsive and better address new societal needs. New Public Governance (NPG), a theme that emerged in the eighties, is about ruling and steering society, and not simply public policy implementation and service delivery. The emergence of NPG was instigated by the inefficiencies of traditional public administration which was riddled with hierarchy and over-regulation. Governance is defined as social steering and decision-making through government institutions in order to: serve the aims, objectives, and priorities of society; deal with the challenges, threats and problems faced by society; and to build and seize opportunities the serve society. Public policy is therefore determined through social steering. Social steering defines the relationships between government, the private sector and society in order to achieve society's goals.

Osborne (2006) argues that there is a need for NPG. Public Administration (PA) works on the premise that society relies fully on government to meet society's needs. PA focuses on and within government and its key elements are: 1) centrality of bureaucracy in policy making and decision making 2) a commitment to incremental budgeting and 3) non-public (external) organizations only viewed as potential elements of the policy system. The strength of PA was that it explored the political nature of governance. It lacked, however, in its vague approach to implementation. In the 1970s New Public Management (NPM) saw significant growth over PA, as NPM improved on implementation by incorporating private sector management techniques. According to Osborne (2006), NPM's key elements were learning from the private sector, focus on performance management, implementation handled separately from policy makers, and external organizations viewed as independent contractors. Even though NPM delivered good implementation, it has been criticized for not evolving from its intra-governmental focus and its view of policy as a secondary issue.

In recent years, NPG has emerged to overcome the problems noted with PA and NPM. NPG posits a pluralist state, where multiple inter-dependent players contribute toward service delivery, and where multiple processes inform the policy making system. As a result, NPG focuses on inter-relationships of governance and processes, and on service effectives and results. NPG therefore combines the strengths of PA and NPM by recognizing the legitimacy and relevance of policy creation, as well the strong implementation required for policy to be impactful (Osborne, 2006).

\subsubsection{Private Governance and Public-Private Partnerships (PPP)}

Börzel and Risse (2005) define public-private partnerships as the formation of cooperative relationships between government, profit-making firms, and non-profit private organizations to fullfil a policy function. There are at least four distinct types of PPPs: 1) co-optation 2) delegation, 3) co-regulation, and 4) self-regulation. In co-optation PPPs, non-state actors offer knowledge, expertise and advice and in exchange receive closer information about negotiations. In delegation PPPs, some functions are delegated to non-state actors. In co-regulation PPPs, non-state actors have equal power with state actors. In self-regulation PPPs, nonstate actors create their own regulation which supersedes state regulation.

Börzel and Risse (2005) argue that there is no empirical evidence that proves that PPPs improve problem-solving ability of governance at an international level. However, several arguments can be made in favour of PPPs: pooling of resources between public and private actors increases the problem-solving capacity and non-state actors serve as knowledge providers. However, the delegation of authority to non-state actors can easily result in problem-shifting rather than problem-solving. In many cases, PPPs amount to deregulation and privatization of service or functions previously performed by the state. What further compounds the problem is that the state cannot easily take back these functions, as it was not able to successfully carry them out to begin with. Next, involvement of stakeholders leads to better governance in terms of a reasoned consensus rather than a bargaining compromise. Private actors contribute to the identification of potential solutions to problems by bringing in expertise and knowledge. As a result, the state becomes open to deliberation.

Brinkerhoff and Brinkerhoff (2011) approach the definition of PPPs as a nuanced definition where a PPP exhibits elements of partnership. These elements are mutuality and organization identity. Mutuality means joint commitment to the partnership's goals, mutual dependence and some degree of equality in decisionmaking. Organization identity refers to the individual competencies and capabilities of the individual partner organizations. The individual partner organization has its own mission, values and identified constituencies. The definition therefore encompasses the cross-sectoral collaboration with the following features in relation to partnership: 1) jointly determined goals, 2) collaborative and consensus-based decision making, 3) nonhierarchical and horizontal structures and processes, 4) trust-based and informal as well as formalized 
relationships, 5) synergistic interactions among partners, and 6) shared accountability for outcomes and results.

The benefit of partnerships is as follows: 1) to enhance efficiency and effectiveness through a reliance on comparative advantages, 2) to provide multi-actor solutions required by the scope and nature of the problems, 3) to move from a no-win situation to a compromise and possibly win-win situation between the multiple actors, and 4) to have an open decision-making process to maximise representation and ensure sustainability. PPPs may be categorized by purpose such as service delivery and infrastructure. The PPPs purposes relevant to this discussion are policy and economic development. PPPs with the purpose of policy have organization structures and processes such as networks, task forces, joint task forces and special commissions. The performance metrics include technical quality, responsiveness, consensus building and legitimacy. Its normative dimensions include equity or representation, citizen participation and transparency (Brinkerhoff and Brinkerhoff, 2011).

\subsubsection{Global Governance}

Brinkerhoff and Brinkerhoff (2011) note that there are five bases of authority for what they call "global governors": institutional, delegated, expert, principled, and capacity. Global governance delegation can blur the relationship between state preferences and outcomes. International norms created by global governance are not always desirable to public actors, even though they form part of the governance.

Backer (2011) introduces the concept of soft laws for the governance of non-state actors in the global arena. Soft laws are not created by a single state, but instead are established through global bodies. State law only applies to the state from which it originates, whereas soft laws span across states and do not depend on the state as either a source or enforcer. Instead, soft laws or voluntary codes are not binding through organs of state enforcement, but are binding through the governance systems of the corporations themselves. This is achieved through consent of the governed and gives soft laws their legitimacy. The source of soft laws is based on the presumption of universal values.

Backer (2011) argues that certification mimics public regulation - a third-party organization creates a set of standards grounded in substantive values for the production of a product and then offers to certify corporate compliance with these standards. Complying companies can then advertise their certification as proof of compliance with a set of third-party standards that advances certain social, economic, political, ethical, or other values.

Backer (2011) concludes that there is a new public transnational level of governance and governance apparatus: it is to set the terms of discussion, as well as to frame regulatory responses and private behavioural norms. It is to produce standards that become law within states and governance norms among private actors. It coordinates and synthesizes. It does not legislate, but produces law; it does not govern, but it produces standards. It does not administer, but it produces information and monitors. The enforcement approach mimics those developed for private governance systems - transparency, benchmarks, exposure, and coercion. Just as multi-nationals have congregated within networks, so too have states.

\subsection{Conclusion}

In examining leadership within entrepreneurship, particularly at the industry level, a number of vantage points were considered: strategic leadership, policy, and governance. Strategic leadership literature gives insights into what entrepreneurship industry leadership may look like and the related potential benefits. Entrepreneurship and public policy literature illuminate factors that need to be considered for a conducive entrepreneurial environment. Governance literature sheds light on shortcomings of government to resolve societal needs, and by extension entrepreneurship needs. PPPs offer suggestions with regards to structuring entrepreneurship governance. The literature, however, reveals that leadership within entrepreneurship, particularly at the industry level, is not well researched.

\section{Methodology}

In order to further examine the state of leadership within entrepreneurship at the macro level, semistructured interviews were conducted with 10 participants. Purposive sampling was used to select the participants. The participants were mostly established entrepreneurs, all having extensive experience (all participants far exceeded the study's minimum of at least 3 years), and owning at least 1 business. The interviewees have been directly involved with entrepreneurship, with appropriate level of experience. It was not considered necessary to constrain participant selection according to industry type, and the participants cover a number of industries.

Government and the private sector are considered as role players and stakeholders impacting on entrepreneurship, but were generally not considered as respondents. However, public servants from select 
parastatals that are heavy invested in entrepreneurship and its success to some extent, like public investment parastatals (The Industrial Development Council (IDC)), and private servants in consultant and related services, also heavy invested in entrepreneurship, such as business chambers, were included to a limited extent ( 2 participants), to open up the discussion, and to obtain a more holistic view. The interviews on average lasted 1 hour. The interviews were recorded, transcribed and subsequently coded.

\section{Results}

\subsection{What is the Effectiveness of EI Leadership? What are the Gaps within EI Leadership?}

Interviews revealed there is a general lack of leadership at the macro level in entrepreneurship. As shown in Figure 1 below, the lack of leadership is based on three categories, namely 1) uncoordinated efforts, 2) lack of mentorship and support and 3) lack of leadership and will among entrepreneurs.

The flow within Figure 1 and related figures are sequenced according to sample quotes, codes, categories and themes.

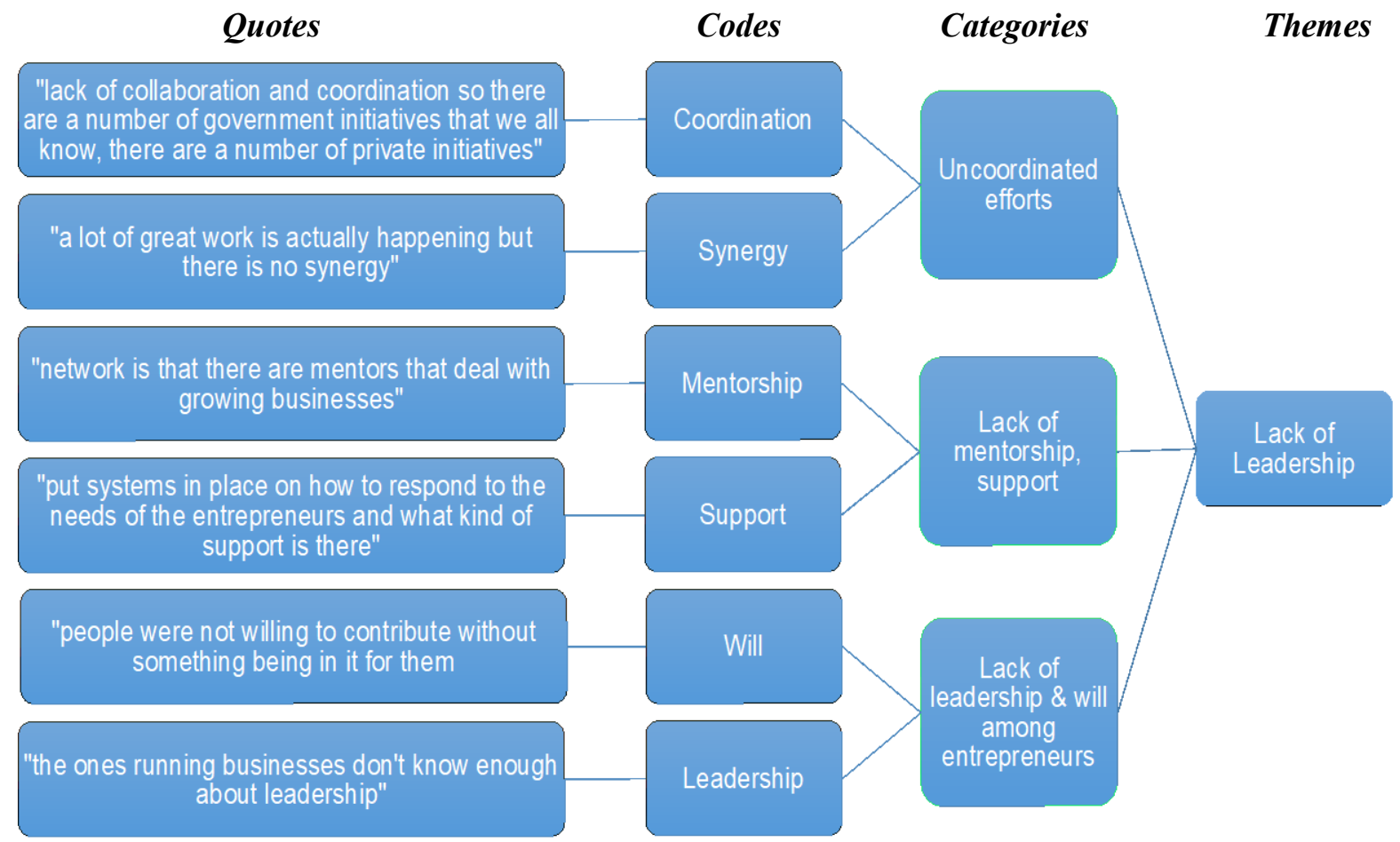

Figure 1. Lack of Leadership

Interviews revealed the entrepreneurs appreciate that there are several private and public sector initiatives to support entrepreneurship. These range from efforts of incubators to help businesses achieve growth, to government initiatives and policies aimed at addressing entrepreneurship challenges. However, these initiatives remain largely uncoordinated and unstructured, resulting in low positive impact on entrepreneurship as a whole. The challenges faced by entrepreneurs are not analyzed, prioritized and dealt with on macro level through coordinated efforts by the various stakeholders. These efforts are also uncoordinated due a lack of proper communication between government, entrepreneurs and the private sector. Other impediments to coordination include competition between stakeholders, such as incubators competing for funding, universities competing for accolades, individual entrepreneurs launching separate, unrelated initiatives, and conflicting interests of stakeholders such as government, entrepreneurs, the private sector and universities.

There is also inadequate monitoring, measurement, vision setting and strategy for entrepreneurship as an industry. Entrepreneurs realize that there is a gap in leadership at the macro level, and appreciate that all stakeholders need to come together to collaborate and synergize for the betterment of the industry and job creation, but show no initiative themselves. The prosperity of entrepreneurship should not only be measured with hard numbers such as the number of jobs created, revenue, profits and size. It should also be measured via soft measures - the development of entrepreneurs, the number of new entrepreneurs, the success and failure rate, and the number of entrepreneurs who have failed in the past but have subsequently become successful. 
These softer measures are more aligned with the prosperity of entrepreneurship and less with the interests of other stakeholders.

Interviews revealed that there are other gaps in EI leadership, such as the lack of a unifying force that represents the mutual interests of entrepreneurs. It must also bring unity within entrepreneurship and become a common voice to government, the private sector and other stakeholders within the entrepreneurship ecosystem. It was also noted that one of the key functions of any group leading entrepreneurship must be to reach a wide range of communities simultaneously, in order to have maximum impact. It should be led by entrepreneurs for entrepreneurs. A steering committee was suggested that would prioritize issues and assist government with policy formulation.

Interviewees explained that there have been efforts to lead entrepreneurship at the macro level by some bodies such as the Chamber of Commerce, and by private individuals such as those who initiated the Hookup Dinner and Start-up Grind. The Chamber of Commerce was supposed to be an aggregation of businesses so that there could be a unified voice to government, but this has not really occurred. Privately launched initiatives such as the Hookup Dinner provide platforms for nascent entrepreneurs to pitch their ideas and receive feedback from other entrepreneurs. However, these private initiatives attract too few entrepreneurs and fail to gain the wide appeal required to lead entrepreneurship at the macro level; the initiatives that have been launched have not been widely successful at the macro level in South Africa. Some of these initiatives failed precisely because of a lack of leadership, because no one was willing to truly lead without some sort of benefit accruing to them. Interviewees believed that in other countries, such as the US, some relatively good initiatives exist, such as the Global Entrepreneurship Network, which tries to connect entrepreneurs globally for ease of scaling. However, the Global Entrepreneurship network is founded in the US and something country specific is still required. South Africa's global networking ability in relation to entrepreneurship is also limited and needs further development. There is no unified voice from South African entrepreneurs to the rest of the world and government is not currently relaying related information in and out and of the country sufficiently.

Interviews revealed that support for the different phases of entrepreneurship is also lacking. Particular emphasis was placed on the lack of guidance during the start-up phase. This was attributed to the lack of a "one-stop-shop" for information, support and guidance for entrepreneurs. In contrast, some entrepreneurs held the view that there is some support, but only for certain types of entrepreneurship, such as job-intensive industries, and results in a lack of support across entrepreneurship as a whole. Entrepreneurs require mentorship over and above access to information, as mentorship provides the practical hands-on advice required in addition to theoretical assistance or training that is currently on offer from incubators.

Interviewees also expressed that the lack of access to information, support, financing and mentorship was an issue facing entrepreneurship. There was no macro level perspective of how entrepreneurs should be supported and no central point of information. For ease of management and information transfer, some interviewees thought that entrepreneurship should be segmented by industry such as agriculture, technology, manufacturing, and medicine for example. Others thought it should be segmented by phases ranging from ideation to the expansion and growth phase, while some thought it should be segmented by region. In all cases the intention would be to serve each segment based on its respective needs.

Interviews showed that there is a lack of capability on the part of entrepreneurs to lead themselves at the macro level. Entrepreneurs are proficient in their respective professions or fields, but there is a deficiency in management skill and leadership. Leading an entrepreneurial venture is different from leading entrepreneurs with the pursuit of creating and attaining shared visions and goals. In contrast, other interviewees revealed that the capability to lead is available among entrepreneurs, but there is a lack of will. In some cases, entrepreneurs believe that no leadership is required and that the essence of being entrepreneurial is finding one's own way; entrepreneurs will take care of themselves. In other cases entrepreneurs don't want to lead themselves because they are survivalist; they will not lead unless there is a financial or other significant benefit in it for them. There is also a cost of bringing everyone together and a debate as to who will bear that cost.

\subsection{What are the Issues and Challenges within EI Leadership?}

Several issues and challenges were raised by interviewees. The findings related to this are shown in Figure 2 and are summarised as follows: 1) Culture 2) Fragmented frameworks and 3) Benchmarking and standards. 


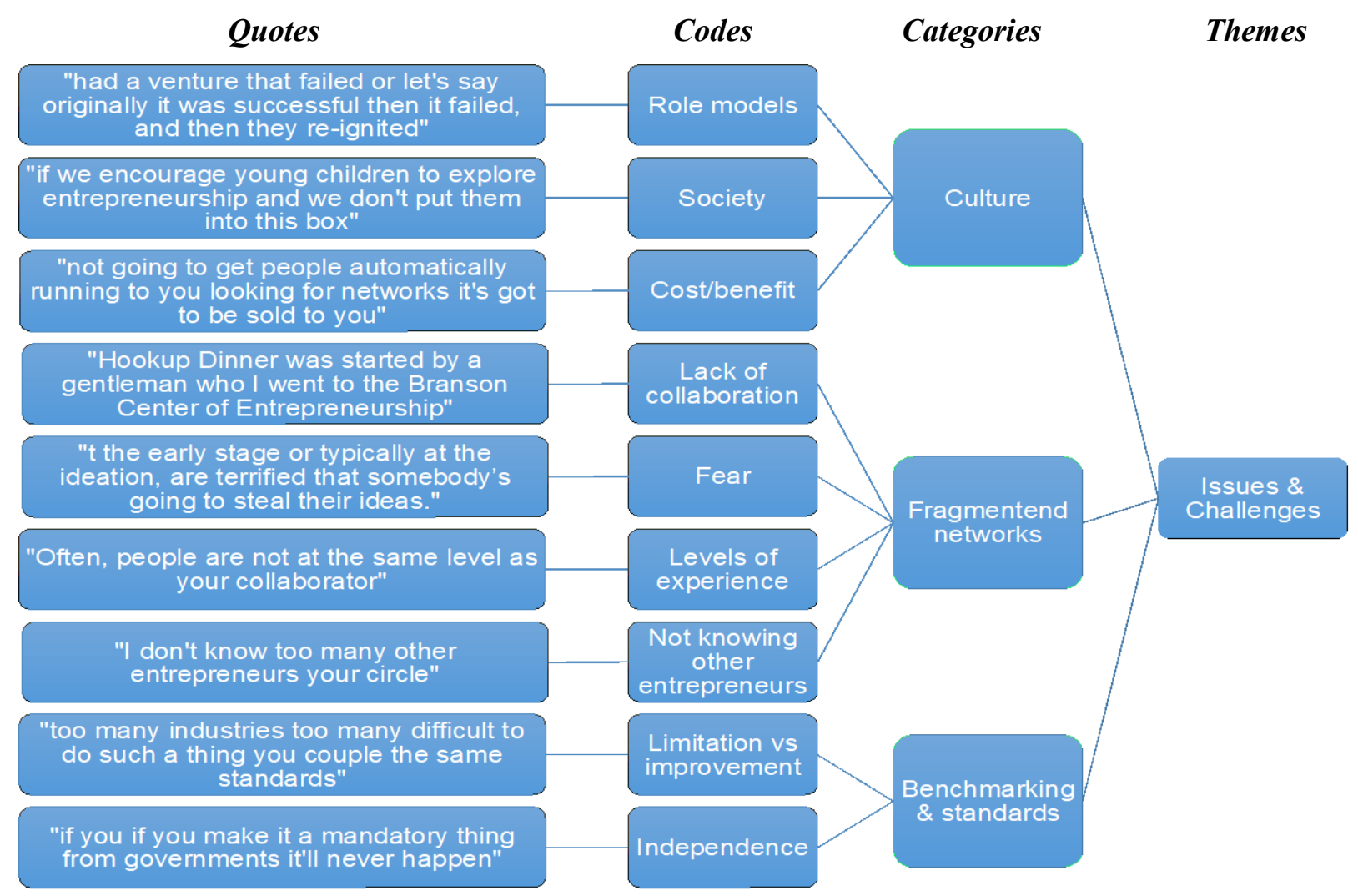

Figure 2. EI leadership issues and challenges

Interviewees felt that the expectation of what an entrepreneur is or should be, and reality are not aligned. Most people think of Steve Jobs, instead of thinking about more relevant local role models who have failed and then succeeded, all within the confines of good ethics. Other role models, such as "tenderpreneurs", who appeared to be relatively successful, were negative for entrepreneurship, as they encouraged the use of political connections to win tenders from government. However, with the correct and relevant local role models in place, entrepreneurs may begin to see the benefit or appeal of joining networks, mentoring and leading in entrepreneurship. The view is that the media is partly to blame for the role models it endorses and advertises, as well as those it overlooks. The government also handpicks a narrow profile of highly successful entrepreneurs to showcase as success stories, and this negatively affects what people perceive as realistic role models in entrepreneurship.

Interviewees also thought that society's view of entrepreneurship influenced the culture and mood among entrepreneurs. Entrepreneurial education for school children at a young age may allow even those who do not want to become entrepreneurs to understand it and its associated challenges better. At the moment, society does not understand entrepreneurship and punishes nascent and incumbent entrepreneurs for failure, instead of encouraging them to try again. Some interviewees explained that South Africa also requires a unique solution to the mood and attitude of entrepreneurship in society and amongst entrepreneurs. In a country with significant levels of inequality, a normal entrepreneurship ecosystem does not exist, and therefore solutions that have worked elsewhere cannot simply be transposed into the South African context.

Some interviewees posited that entrepreneurs are responsible for the mood and culture within entrepreneurship; entrepreneurs themselves must take entrepreneurship seriously by organizing themselves more systemically, as has been done in innovation in Kenya, where entrepreneurs lead and government follows. Interviewees also revealed that entrepreneurs may not lead themselves, unless it is appealing to do so; the individual benefit of leading or joining networking organizations should outweigh the cost to entrepreneurs. Interviewees argued that there was no single body that was accountable for the culture and mood of entrepreneurship. Government was making efforts to do so, but was not being held accountable by itself or others, and could not change the culture without the support of the other stakeholders in the ecosystem. Improved levels of dialogue, interaction and synergy between and within the various stakeholder groups would improve the persisting negative and self-centered culture within entrepreneurship.

Interviewees knew of several entrepreneur related networks and organizations such as the Hookup Dinner, but indicated that these were largely disjointed or fragmented. There was no coordination between 
them and some of them had very similar objectives. However, there were very few follow-up actions taken after forums, as there was a lack of accountability. Entrepreneurs were also not keen to share and collaborate due to fear of their ideas being stolen or being challenged on their viability. It also became apparent that entrepreneurship is a lonely journey and entrepreneurs do not know each other outside the confines of their immediate business needs. Once again, some interviewees intimated that another cultural issue emerged; experienced entrepreneurs may not share knowledge or collaborate if there is no benefit in it for them, particularly if they are more experienced than their counterpart collaborators.

Interviewees explained that there are generally no standards, benchmarks or governance in place for entrepreneurship at the macro level. The reasons for this remain unclear, but some interviewees alluded that unlike a profession such as accounting, entrepreneurship may be too broad for general guidelines to be relevantly applied. Some interviews felt all entrepreneurs could benefit from basic structure and governance, and basic guidelines should be in place. Many entrepreneurs start businesses without knowing what systems they should have in place to safeguard the sustainability of their businesses. This ranges from accounting systems and operations systems, to strategy and contingency planning. Some nascent and experienced entrepreneurs do not have sufficient knowledge of basic finance and competitor analysis, which are basic requirements for sourcing funding from investors. Interviewees felt that financial resources or funding for entrepreneurship are adequately available in South Africa, through various private and public organizations such as the IDC (Industrial Development Council). However, entrepreneurs do not know how to access these funds, or how to present themselves sufficiently, to have access to these funds.

Interviewees indicated that entrepreneurs are fiercely independent, and imposing any sort of rules or standards on them would be received negatively. Instead, if benchmarking, standards and governance were introduced as a suggestion or recommendation, then that may lead to a positive culture change. Concern was expressed at the type of standards or benchmarking to be used, as entrepreneurship is very broad and the manner in which standards could be applied uniformly remain unclear. Overall, standards or benchmarking should improve their output, and must not limit or hinder entrepreneurs.

\subsection{What is the Role and Contribution of Government?}

A shown in Figure 3, interviews revealed that there are several facets related to government. These are categorised as follows: 1) Relationship with entrepreneurs, 2) Facilitation of initiatives and decentralization, 3) Policy and 4) Political agenda.

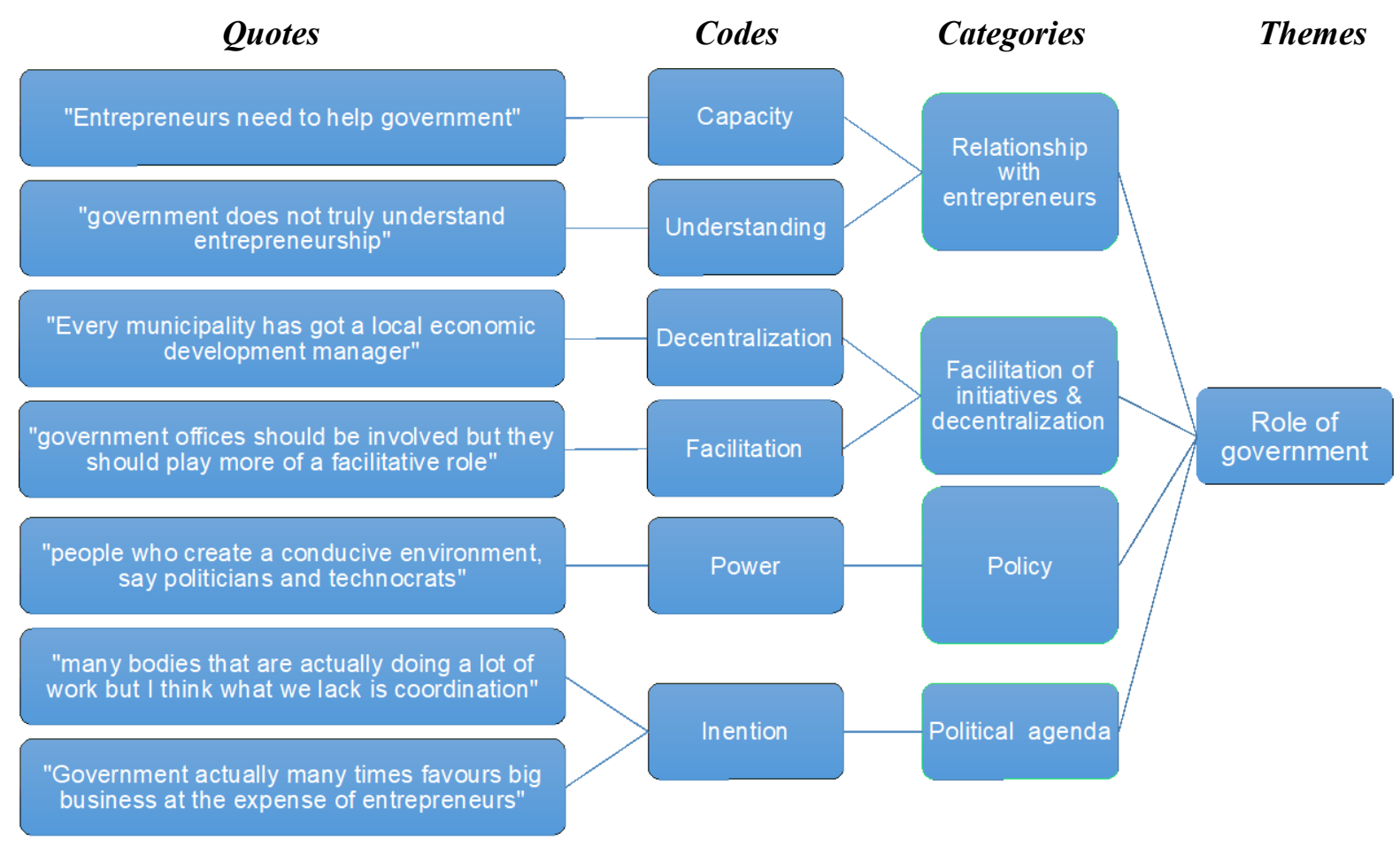

Figure 3. The role of government

Interviewees believe that the relationship between government and entrepreneurs is disjointed, stifled and not progressive. Government does not adequately listen to and understand the needs of entrepreneurs. One 
reason could be that government does not create platforms to suitably engage entrepreneurs from different sectors, backgrounds and growth stages. On other hand, entrepreneurs have not organized themselves sufficiently to have a unified voice to government. Government also frequently lumps Small to Medium Enterprises with entrepreneurship, instead of distinguishing between the two and managing them separately. There is a disconnect between government expressing the need to grow entrepreneurship, and their inability to engage entrepreneurs. There is also a disconnect between entrepreneurs wanting to be heard by government, but failing to create representative groups in order to clearly communicate and engage with government. There is also the notion that government does not have the capacity or capability to adequately support entrepreneurs, as government officials do not have a background in entrepreneurship, and lack experience in this particular field. This negatively affects the perspective that entrepreneurs have of government.

Interviewees proposed that the role of government is not to lead entrepreneurship. Instead, government should facilitate the growth of entrepreneurship through properly implemented initiatives and decentralized leadership at municipal level, that can adapt and respond to entrepreneurship related needs. Some interviewees explained that in many instances where government is invited to participate or engage entrepreneurs, government is either not responsive or tries to lead, control and influence entrepreneurship, instead of listening and facilitating growth. This leads to a lack of trust of government by entrepreneurs. The interests of government and entrepreneurs are not always aligned. Government wants to use entrepreneurship for job creation and economic development, but does not always focus on the prosperity and needs of entrepreneurs. These needs range from less complex policy, less bureaucracy in starting a business, more control and accountability of big business by government, and the development of entrepreneurs. Other interviewees expect government to hold the private sector accountable for their lack of interest or inaction in supporting entrepreneurship. Enterprise and social development was cited as an example of the private sector simply throwing money at the problem, instead of truly helping and developing entrepreneurs. Government does not adequately measure private businesses on their ability to improve their supply chain through meaningful initiatives, but instead measures them on how much was spent. Some interviewees even suggest that perhaps government favours big business over nascent entrepreneurs, as some policy favours the former.

Interviewees explained that government has significant power over entrepreneurship through the creation of a conducive environment and policy. Government creates a conducive environment through enforcement of the law, but entrepreneurs will also continue to do their utmost to do business even in difficult environments. Policy is vital for entrepreneurship and several interviewees had ideas on policy changes that could benefit entrepreneurship such as easier tax compliance, less compliance required during the start-up phase and incentivizing learnerships. Some interviewees believe that government is listening to entrepreneurs, as evidenced by some policies such as small business tax, but that the impact of policy seems slow and that entrepreneurs are "impatient". On the other hand, government policy is complex, cumbersome and filled with "red tape" for nascent and incumbent entrepreneurs to navigate. It discourages entrepreneurship by requiring enormous amounts of time and effort to focus on compliance, instead of starting or running a business. Government cannot expect a small business to comply with all the regulations that a large business must comply with when small businesses have limited capacity. Other instances of government failure in relation to the private sector and entrepreneurship is that government is not advocating that banks help fund entrepreneurship.

Some entrepreneurs believe that government has the best interests of entrepreneurs at heart, while others expressed concern that government is only focused on its own political agenda. The former group of interviewees further explained that government has the best intentions, but lacks in capability and internal coordination, with several departments not knowing what the other is doing. The latter group elaborated that entrepreneurs have low levels of trust in government, as government leadership changes with each administration, and the new leadership may change policy or direction in order to suit their political interests. Some interviewees felt that government does not take entrepreneurship seriously, as evidenced by government's consistent late payment to businesses for services rendered. Other interviewees expressed that government is not held accountable for the success or failure of entrepreneurship, and only highlights the rare success stories in order to convince society that it is making progress.

\subsection{What is the Role and Contribution of the Private Sector?}

Interviews with entrepreneurs revealed that there are several factors related to the private sector and other stakeholders as shown in Figure 4. Namely these are: 1) private sector relationships with other stakeholders, 2) the role of incubators and accelerators, and 3) the role of universities and other research organizations. 


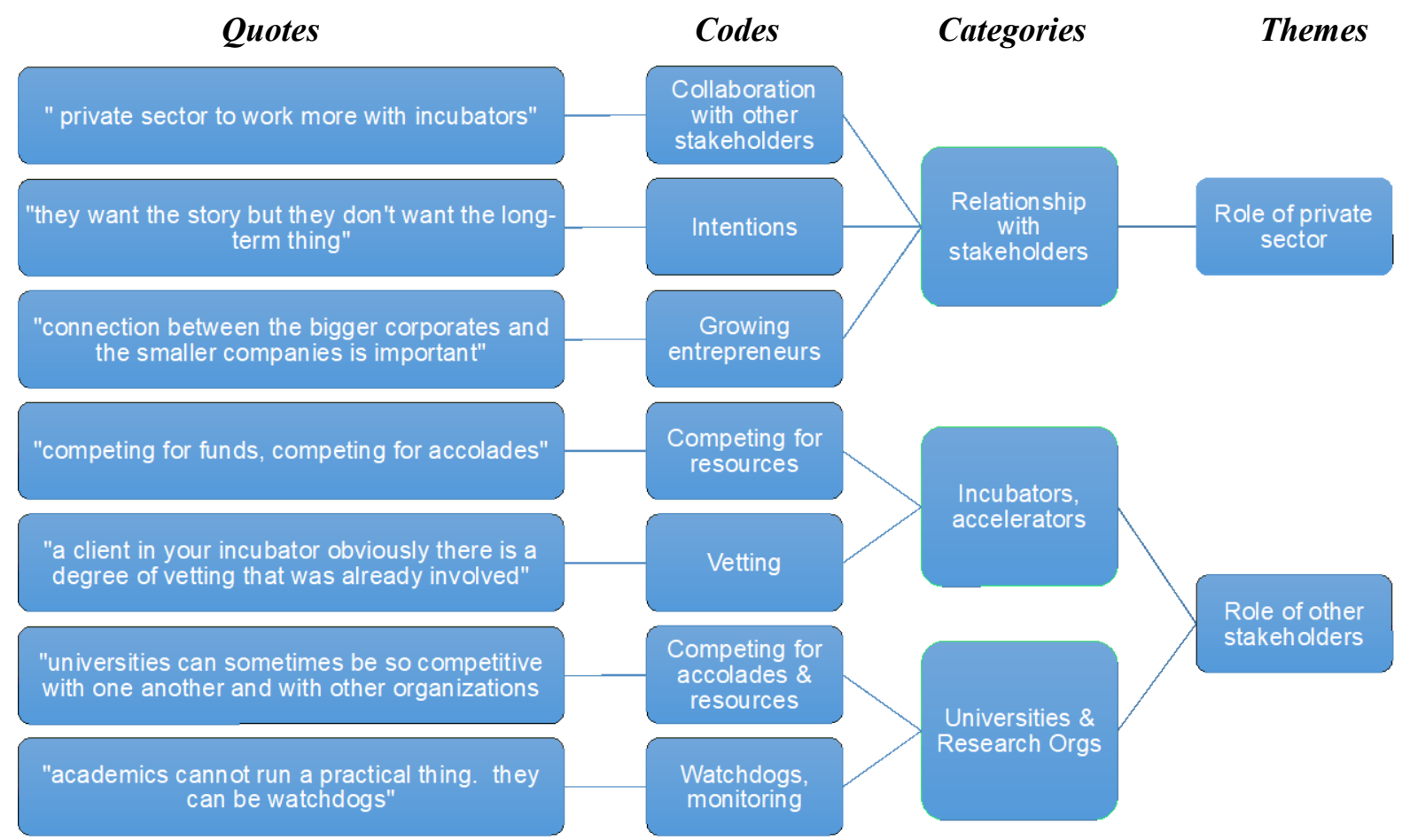

Figure 4. The private sector and other stakeholders

Interviewees felt that the private sector was not adequately fulfilling its role in the support and development of entrepreneurship. Large corporates should collaborate more with other stakeholders such as incubators, accelerators and government to find ways to support and grow entrepreneurs. The role of large corporations should be to support entrepreneurs through meaningful enterprise development as well as becoming partners, clients and suppliers to entrepreneurs. Large corporations should play a central role in entrepreneurship, but interviewees felt that they were failing to do so and were not being held accountable in their failings. Most interviewees think that large corporates have a supportive role in the leadership of entrepreneurship, but should not lead as they do not have the best interests of entrepreneurs at heart.

The private sector wanted the brand recognition that was associated with uplifting entrepreneurs, but not the required long term commitment to make a real difference. Large corporates threw money at the problem of enterprise development, instead of truly developing entrepreneurs that would eventually becoming strategic suppliers. Interviewees questioned the intentions of the private sector, and doubted if the private sector understood entrepreneurs, as most private sector employees have little or no entrepreneurship experience and are limited to corporate experience.

There is also insufficient dialogue between large corporates and entrepreneurs, even though large corporates have large, well organized bodies that represent them well. Entrepreneurs, however, are not well organized to clearly communicate their position to large corporates. Large corporations also saw failures of entrepreneurs negatively, instead of as a stepping stone to future success. Interviewees felt that large corporates did not trust entrepreneurs to deliver the quality, scale and speed of products and services required. Entrepreneurs felt that large corporations were not patient enough to integrate entrepreneurs into their business, by means of processes or systems that minimize mistakes. Large corporations did not understand the constraints and challenges of entrepreneurs.

Other interviewees felt that there was a positive change in the relationship between entrepreneurs and large corporations. Entrepreneurs, due to their smaller size and agility, are able to supply innovation and solutions faster and better than large corporates. Large corporates are starting to see the value in collaborating with entrepreneurs, and smaller companies are starting to realize the benefit of doing business with large corporates. However, there are also competing interests between large corporates and entrepreneurs as in some instances they compete for the same clients and markets. This would cause strained relationships between corporates and entrepreneurs, and large corporates not wanting to support entrepreneurs. Entrepreneurs would also not want to share ideas and collaborate with large corporates, due to fear of idea theft, or large corporates taking over or buying the entrepreneur's business, resulting in the loss of autonomy or the business. Large corporates are businesses themselves and their primary focus would not be to encourage entrepreneurship, but rather to maximize their own profits and shareholder value. 
Other stakeholders such as universities emerged as important stakeholders that are not adequately supporting entrepreneurship. Interviewees thought that universities are starting to teach entrepreneurship models and theories, but were still focusing on teaching methods that suited large corporates, more than they suited entrepreneurs. Universities also compete amongst each other and other stakeholders for funding and recognition, instead of focusing on outcomes that support entrepreneurship. Universities could contribute to entrepreneurship by becoming watchdogs or regulators, providing research, knowledge and data, as well as continuous monitoring of entrepreneurship as a whole. Incubators and accelerators also have the challenge of competing for funding, as some of them are government funded. They also have to remain sustainable and compete with each other for clients. This makes collaboration between them difficult to achieve and stifles support for entrepreneurs. The role of incubators could be to vet entrepreneurs before they do business with corporations, in order to ensure a certain level of competency in the entrepreneur. They could also link entrepreneurs with large corporates. But in order for their vetting process to be generally accepted, accreditation of incubators would be required. Some interviewees felt that some incubators are setting vision and monitoring entrepreneurship well, but are limited to only the entrepreneurs that they have direct contact with.

\section{Discussion}

Entrepreneurship is not well led at the macro level and is instead segregated into regions, clusters and industries and often interchanged with SMEs. It is misunderstood by governments and policy makers and is driven by uncoordinated efforts of governments, incubators, accelerators and other private entities.

\subsection{What is the Effectiveness of Leadership of Entrepreneurship at the Macro Level? What are the Gaps within EI Leadership?}

The results indicate that there is a general lack of leadership of entrepreneurship at the macro level. Several private and public sector initiatives exist to support entrepreneurship, but remain largely uncoordinated. Also, the challenges faced by entrepreneurs are not adequately analyzed and prioritized. There is little vision setting, strategy, monitoring and measurement of the prosperity of entrepreneurship at the macro level. Entrepreneurship lacks a unified voice, and does not jointly voice its needs to other stakeholders such as government, the private sector and academics. Policy makers often misunderstand entrepreneurs. Stakeholders have competing and conflicting interests, and are self-centered. Leadership should bring all stakeholders together, create synergies and allocate non-competing roles.

The leadership approaches currently employed are ineffective. There is also a lack of will to lead among entrepreneurs without some sort of benefit being accrued. Entrepreneurs have individualistic or survivalist mentalities, and narrowly focus on their individual, immediate interests, instead of the well-being of entrepreneurship as a whole. There is a lack of leadership development among entrepreneurs, particularly with regards to their leadership style and perceptions of leading the entrepreneurship industry itself, over and above leading their individual businesses. Strong strategic leadership should offer evolution, innovation and vision setting for entrepreneurs at the macro level.

There is a lack of mentorship, information, guidance, advice and support for new entrepreneurs, also from experienced entrepreneurs. There is a lack of mentorship, and thus collaboration, overall, as all levels of entrepreneurs benefit from it. The type of leadership style demonstrated by government is not suitable for entrepreneurship.

\subsection{What are the Issues and Challenges within EI Leadership?}

Culture permeates most issues, such as fragmented networks, the lack of collaboration and the lack of standards in entrepreneurship. From a leadership perspective, at the macro level, entrepreneurship has a negative and poor culture, image and identity. The culture is adversely affected by the lack of realistic, positive role models and the lack of understanding and encouragement of entrepreneurs by other stakeholders and society. The lack of understanding may be due to a lack of knowledge of entrepreneurship in society in general.

Attempts to form networks have not been widely successful. Fear, lack of trust, and disparate levels of experience create barriers to sharing and collaboration amongst entrepreneurs. Entrepreneurs do not really know each other. All of this leads to fragmented and disjointed networks.

There is a general lack of standards and benchmarking in entrepreneurship at the macro level. This may be due to autonomy and diversity within entrepreneurship. However, there should still be benefits accruable from general guidelines, governance and strategy frameworks. 


\subsection{What is the Role and Contribution of Government?}

Government has the capacity to assist entrepreneurs but lacks in knowledge, skills, expertise and capability. The government fails to understand and communicate with entrepreneurs. Entrepreneurs also fail to adequately communicate with government, due to lack of a unified voice. Government does not know how to assist entrepreneurs and uses an inappropriate leadership style. Entrepreneurs distrust the motives behind the government's actions. There is a lack of accountability on the part of government for the failures of entrepreneurship - there are little performance or evaluation metrics government is held to, and little to no consequences for government failing. The role of government is not to lead entrepreneurs, but rather to facilitate growth and provide support through decentralized centers that can quickly adapt to the needs of local entrepreneurs. Government could also look at its own culture in the context of entrepreneurship, and incorporate more entrepreneurs in its departments and centers.

Entrepreneurs believe that the government has a significant amount of power and influence over entrepreneurship through policy-making and bureaucracy. However, entrepreneurs also question the government's agenda and whether government has entrepreneurs' best interests at heart. Views are that government appears to favour large corporates over entrepreneurs. Several examples of policy changes that could benefit entrepreneurship were also cited by entrepreneurs.

\subsection{What is the role and contribution of the private sector}

The private sector comprises several stakeholders, namely: incubators and accelerators, private business or corporates, and universities. The contribution of all these stakeholders to entrepreneurship leadership at the macro level is lacking. The wrong incentives may instigate the wrong behaviour. A lot of competition persist among the stakeholders, with little collaboration towards common goals. Large corporations have a lot to contribute to entrepreneurship and its leadership. However, corporations may not be fully committed to entrepreneurship, due to competing and conflicting interests. Entrepreneurs believe that large corporates are not adequately fulfilling their role. There is poor monitoring and evaluation of the relationship and partnership between entrepreneurs and large corporates.

\subsection{The Way Forward}

Culture permeates all aspects of entrepreneurship and entrepreneurship leadership - from issues related to each of the stakeholders to how entrepreneurs view themselves. The current culture within entrepreneurship is negative and must be cultivated. Entrepreneurship culture includes role models and the perspective of society regarding entrepreneurship. The culture amongst entrepreneurs needs to transform from survivalists entrepreneurs looking after their own interests, to entrepreneurs that reach higher levels of development and specialization, and that work together for the greater good. Entrepreneurship ultimately needs to develop an unified voice, and lead itself. Relationships and trust must be cultivated within entrepreneurship. Overall, entrepreneurship will benefit from greater mentorship at all levels. Government must develop its ability to listen to entrepreneurs and reconsider its leadership style when it comes to entrepreneurship.

Public-private-partnerships (PPPs) offer a number of propositions and principles to improve entrepreneurship leadership at the macro level. Non conventional leadership styles, like servant leadership, could help to resolve the competing agendas of stakeholders, increase mutual collaboration and benefit among stakeholders, and resolve the challenges of entrepreneurship leadership at the macro level in general.

It is believed that greater entrepreneurship leadership at the macro level would lead to entrepreneurs and the stakeholders of entrepreneurship reaching higher levels of development, collaboration and specialization, and that it would consequently unlock additional potential for value creation and venturing, thereby further growing and maturing entrepreneurship. Better entrepreneurship leadership at the macro level would provide direction, vision and strategy to the entrepreneurship industry. Entrepreneurship is immortal, but it is not truly evolving - it is not getting past infancy.

\subsection{Recommendations for Further Research}

The study has shown that there is a lack of leadership of entrepreneurship at the macro level. Some of the issues and challenges include a negative culture, fragmented frameworks and the lack of benchmarking and standards. The roles of government and the private sector have been defined by entrepreneurs as facilitators, mentors and clients. The study only served as an introductory study, and recommendations for further research abounds:

- Evaluating whether government leading entrepreneurship is truly optimal, and investigating who the optimal leader of entrepreneurship is. 
- The way towards enabling entrepreneurship to lead itself.

- The needs and roles of each stakeholder within entrepreneurship. This would be useful in determining how to lead entrepreneurship at the macro level, by improving coordination and synergy between the various stakeholders.

- The optimal leadership style(s) for government as candidate leader of entrepreneurship, and for entrepreneurship leadership overall.

- Spiritual and servant leadership as leadership styles that may potentially overcome the challenges of entrepreneurship leadership.

- Mentorship and leadership development within entrepreneurship, particularly leadership development of entrepreneurs, to further support entrepreneurship leadership.

- Strategy, vision and direction formation and setting in the context of entrepreneurship leadership at the macro level.

- Optimal entrepreneurship culture, and culture development and setting as part of entrepreneurship leadership.

- The perceptions of entrepreneurs regarding collaboration at higher levels.

- The formation of strong institutions, and how it relates to entrepreneurship and entrepreneurship leadership. Put differently, what strong institutions would mean in the context of entrepreneurship and entrepreneurship leadership, and the contribution strong institutions can provide entrepreneurship and entrepreneurship leadership.

- The issues and challenges related to accreditation, standards and benchmarks for entrepreneurship and entrepreneurship leadership, particularly at the macro level. This would be useful for the actual creation and implementation of accreditation, standards and benchmarks for entrepreneurship.

\section{References}

Abor, J. and Adjasi, C. K., 2007. Corporate governance and the small and medium enterprises sector: theory and implications. The International Journal of Business in Society, 7(2), pp.111-122.

Aernoudt, R., 2004. Incubators: tool for entrepreneurship?. Small business economics, 23(2), pp.127135.

Audretsch, D. B., 2003. Entrepreneurship policy and the strategic management of places. In Hart, D.M. (ed) The emergence of entrepreneurship policy: Governance, start-ups, and growth in the US knowledge economy. Cambridge: Cambridge University Press, pp.20-38.

Backer, L. C., 2011. Private actors and public governance beyond the state: the multinational corporation, the Financial Stability Board, and the global governance order. Indiana Journal of Global Legal Studies, 18(2), pp.751-802.

Bhasin, B. and Venkataramany, S., 2010. Globalization of entrepreneurship: Policy considerations for SME development in Indonesia. The International Business and Economics Research Journal, 9(4), p.95.

Boal, K. B. and Schultz, P. L., 2007. Strategic leadership research: Moving on. The Leadership Quarterly, 11(4), pp.515-549.

Börzel, T. A. and Risse, T., 2005. Public-private partnerships: Effective and legitimate tools of international governance. In Grande, E. and Pauly, L. W. (Eds.) Complex sovereignty: Reconstructing political authority in the twenty first century. Toronto: University of Toronto Press, pp.195-216.

Brinkerhoff, D. W. and Brinkerhoff, J. M., 2011. Public-private partnerships: Perspectives on purposes, publicness, and good governance. Public Administration and Development, 31(1), p.214.

Dahlstrand, A. L. and Stevenson, L., 2010. Innovative entrepreneurship policy: linking innovation and entrepreneurship in a European context. Annals of Innovation and Entrepreneurship, 1(1), pp.5602.

Davies, B. J. and Davies, B., 2004. Strategic leadership. School leadership and management, 24(1), pp.29-38.

Elenkov, D. S., Judge, W. and Wright, P., 2005. Strategic leadership and executive innovation influence: an international multi-cluster comparative study. Strategic Management Journal, 26(7), pp.665-682.

Hart, D. M., 2003. The emergence of entrepreneurship policy: governance, start-ups, and growth in. Cambridge: Cambridge University Press.

Henrekson, M. and Johansson, D., 2010. Gazelles as job creators: a survey and interpretation of the evidence. Small Business Economics, 35(2), pp.227-244.

Henrekson, M. and Stenkula, M., 2010. Entrepreneurship and Public Policy. In: Acs Z., Audretsch D. (eds) Handbook of Entrepreneurship Research. International Handbook Series on Entrepreneurship, vol 5., 
pp.595-637. New York, NY: Springer.

Ireland, R. D. and Hitt, M. A., 1999. Achieving and maintaining strategic competitiveness in the $21 \mathrm{st}$ century: The role of strategic leadership. The Academy of Management Executive 13(1), pp.43-57.

Jansen, J. J., Vera, D. and Crossan, M., 2009. Strategic leadership for exploration and exploitation: The moderating role of environmental dynamism. The Leadership Quarterly, 20(1), pp.5-18.

Leithwood, K., Jantzi, D., Earl, L., Watson, N., Levin, B. and Fullan, M., 2004. Strategic leadership for large-scale reform: the case of England's national literacy and numeracy strategy. School Leadership and Management, 24(1), pp.57-79.

Osborne, S. P., 2006. The New Public Governance? Public Management Review, 8(3), pp.377-378.

Resick, C. J., Whitman, D. S., Weingarden, S. M. and Hiller, N. J., 2009. The bright-side and the darkside of CEO personality: examining core self-evaluations, narcissim, transformational leadership, and strategic influence. Journal of Applied Psychology, 94(6), p.1365.

Rowe, G., 2001. Creating wealth in organizations: The role of strategic leadership. The Academy of Management Executive, 15(1), pp.81-94.

Saxien, A., 2000. Silicon Valley's new immigrant entrepreneurs. Santa Cruz: University of California.

Stevenson, L. and Lundström, A., 2001. Patterns and trends in entrepreneurship/SME policy and practice in ten economies. Vol. 3. Stockholm: Swedish Foundation for Small Business Research.

Thomas, T., Schermerhorn, J. R., Dienhart, J. W. and Bartles, D. L., 2004. Strategic leadership of ethical behavior in business. The Academy of Management Executive, 18(2), pp.56-66.

Vera, D. and Crossan, M., 2004. Strategic leadership and organizational learning. Academy of management review, 29(2), pp.222-240.

Villanueva, L. F., 2015. The New Public Governance? Emerging perspectives on the theory and practice of public governance. Journal of Public Governance and Policy: Latin American Review, 1(1), pp.126134. 